\title{
A Study on the Functions, Target, Influential Factors and Evaluation System of Science Popularization Capability Construction of University Science and Technology Parks
}

\author{
Xinming Han1,2, Shukun Tang1, Li Zhao² \\ ${ }^{1}$ Science Communication R\&D Center, University of Science and Technology of China, Hefei, China \\ ${ }^{2}$ Southwest University of Science and Technology, Mianyang, China \\ Email: 107792689@qq.com, sktang@ustc.edu.cn, zhaoli8533@163.com
}

How to cite this paper: Han, X.M., Tang, S.K. and Zhao, L. (2017) A Study on the Functions, Target, Influential Factors and Evaluation System of Science Popularization Capability Construction of University Science and Technology Parks. Open Journal of Social Sciences, 5, 21-37.

https://doi.org/10.4236/jss.2017.511003

Received: October 13, 2017

Accepted: November 5, 2017

Published: November 8, 2017

Copyright (ङ 2017 by authors and Scientific Research Publishing Inc. This work is licensed under the Creative Commons Attribution International License (CC BY 4.0).

http://creativecommons.org/licenses/by/4.0/

(c) (i) Open Access

\begin{abstract}
At present, the scientific literacy of Chinese citizens is still at a low level, and it is still a long way to go for the nation to improve its science popularization capability. University science and technology park is a gathering place and transformation hub for its scientific and technological achievements, which is crucial for promoting the national career of science communication. This paper starts from the definition of science popularization capability of university science and technology park. The study illustrates the basic functions of science popularization capability construction of university science and technology park in three aspects: speeding up the transformation university scientific and technological achievements; improving the quality of innovative and entrepreneurial talents cultivation; promoting the scientific literacy of university and local area citizens. The essay also puts forward the ultimate goal for the science popularization capacity construction of university science and technology park. It analyzes its key influential factors on science popularization capability construction: science popularization environment; the popularization ability on science and technology resources; communication skills and operation on science popularization jobs. At last, the paper constructs the evaluation system of science popularization ability of university science and technology park.
\end{abstract}

\section{Keywords}

University Science and Technology Park, Science Popularization Capacity, Construction Goal, Influential Factors, Evaluation System 


\section{Introduction}

The basic scientific literacy of citizens is necessary to understand the knowledge of science and technology, master the basic scientific method, scientific thinking, scientific spirit, and has the ability to apply them to deal with practical problems, to participate in public affairs. The citizens' scientific literacy can be measured by surveying the proportion of citizens in the three areas of "understanding scientific knowledge, understanding scientific methods, and understanding the impact of science and technology on individuals and society" [1]. According to the latest data of China's ninth national census of scientific literacy, it shows that the proportion of citizens with basic scientific literacy in China is $6.20 \%$ by 2015 , and only those of Shanghai and Beijing are $18.71 \%$ and $17.56 \%$, beyond $15 \%$ [2]. As early as the early 20th century, the proportion of the basic public scientific literacy of the United States has reached 17\% [3]. From these data comparison, it can be found that there is certain gap between China and western countries about the basic scientific literacy of citizens, so that there are many tasks that need to be completed.

With the rapid development of science and technology, citizens' scientific literacy has become an important part of the national comprehensive strength and become one of the core elements of the advanced productive forces. Therefore, for a country, if the level of civic scientific literacy has been at a low level, it will inevitably be at a disadvantage in international competition. Therefore, the CPC Central Committee early in the 18th report clearly pointed out that China should plan and promote innovation from the global vision, improve the original innovation, integration and innovation and the introduction of digestion and absorption of new capacity, and pay more attention to collaborative innovation, to build socialist cultural power and improve the scientific quality of the people. This statement laid the core position of implementation of innovation-driven development strategy, putting forward requirements about promoting scientific and technological innovation and directing the construction of science and technology [4].

Science Park is the gathering place and transformation hub of scientific and technological achievements in colleges and universities. It is the main front for cultivating high-quality innovation and entrepreneurial talents, and occupies an important position in promoting national science popularization, such as the Stanford Science Park in the United States, the Science Park of Cambridge University in Britain, the University of Tsukuba Science Park in Japan, and the Science and Technology Park of Tsinghua University in China, and so on. In the full implementation of the spirit of the 18th Party Congress and building an innovative country, Science Park should be soberly aware of their own importance and consciously strengthen the science and technology capacity, which has a very great significance for the realization of regional innovation-driven development and improvement of citizenship quality in the city. 


\section{The Capability Construction of Scientific Popularization of Science Park and Its Basic Function}

\subsection{Definition of Scientific Popularization of Science Park}

So far, scientific popularization is not a unified definition and its related descriptions scatter in the country's documents and scholars' the research results. In 2007, the Ministry of Science and Technology and other eight ministries jointly issued a number of opinions on strengthening construction of national science and technology capacity. The document describes the national scientific popularization which means that a country should have the comprehensive strength to provide scientific products and services for the public, including science and technology writings, communication channels, education system, social organization network, talents, government macro management and so on. The former director of the Institute of Science and Technology, Ren Fujun, argued that the science and technology ability is part of the science and technology resources, as the basic conditions, including policy environment, personnel, material, organization and science information [5]. Yu Jiagui thought that science ability is to adapt and meet the needs of public through various means [6]. Li Hanjin has defined the ability of scientific popularization in colleges and universities that it is the comprehensive strength of science popularization to provide scientific products and services for the public, including policy environment, infrastructure construction, fund investment and personnel construction and management, creation and dissemination, resources transformation, channels, results and theoretical research ability [7]. Based on the above discussion, this paper argues that the construction of scientific popularization of science park in colleges and universities refers that science and technology park as the subject uses its own superiority condition and enhance the science popularization effect through various investment measures, in order to satisfy the public science demand, and science and technology park can effectively integrate and disseminate science and technology knowledge, promote scientific and technological achievements, and efficiently allocate scientific and technological information resources timely.

\subsection{Definition of Capability Construction of Scientific Popularization of Science Park}

The term "capacity construction" consists of two words. In terms of capacity construction for human beings, domestic scholars Lei Ming argued that capacity building is the process of education, training, configuration, application, management and stimulation by all kinds of subjects (such as countries, communities, organizations, families, etc.) to develop people's potential and promote social and human development, so that as the main subject human beings can continue to enhance the quality and constantly improve themselves [8]. In terms of organizational capacity construction, different areas of research have different views. And the theory of human capital investment in western economics, the 
theory of core competence in western management, and the theory of social stratification and capacity building in western sociology and sociology of development, have explained it respectively.

On the basis of these expositions, this paper argues that the capability construction of scientific popularization is to develop the potentials of science subjects and science and technology park and stimulate their creativity, through cultivating the scientific subjects human beings, building organization with high quality, and improving the objective conditions fully and correctly, so that the science park and science subjects can rely on their own efforts to continuously improve the performance of science. Therefore, the construction of science and technology popularization ability is not only the process of improving the ability of individual subjects, but also the transformation process of the objective environment which is conducive to the full and effective development of the individual. Specifically, the capacity construction mainly includes three aspects. First, the dissemination individual should build the capacity of self-survival and development in the organization; second, the adaptability of organizational changes should be built to promote the individual's ability; third is environment construction to promote the development of individuals or organizations [8].

\subsection{Functions of Capability Construction of Scientific Popularization of Science Park}

According to the provisions of Article 15 of the Law of the People's Republic of China, the Popularization of Science and Technology, scientific research and technology development institutions, institutions of higher education, natural and social sciences groups should organize and support science and technology workers and teachers to carry out scientific popularization activities and encourage them to spread science through their own work [9]; conditionally, the laboratory and showroom, as well as other venues and facilities, should be opened to the public, seminars should be held, and advice should be given. According to this provision, the science and technology park should rely on its own unique advantages, and constantly strengthen the awareness of popularizing science, and enhance the popularizing ability, increase the strength, and promote the development of science and technology, to cultivate innovative and entrepreneurial talent, improving regional public scientific literacy and building a well-off society. To strengthen the capacity construction of science and technology park, its roles are presented as follow.

First of all, the park should strengthen their own capacity construction of science and technology popularization, and to a certain extent improve the efficiency of scientific and technological achievements in colleges and universities. At present, the low conversion rate of scientific and technological achievements in domestic universities is an indisputable fact. The author did a survey about the reasons for the low rate of scientific and technological transformation in the five colleges and universities in Sichuan, and the results show that $39.3 \%$ believe disjoint of scientific and technological achievements and market, $22.6 \%$ agree 
that the scientific environment and market demand is not synchronized, $20.5 \%$ think there is lack of intermediary organizations, $10.7 \%$ believe that there is lack of the dissemination of scientific and technological achievements platform, and $6.9 \%$ think of other factors. It can be seen that building a platform for the dissemination of scientific and technological achievements and further improving the awareness rate of scientific and technological achievements can improve the conversion rate of scientific and technological achievements in colleges and universities to a certain extent. The emergence of science and technology park, to a certain extent, can solve the problem of the lack of communication platform, but may fail to solve the problem of how to improve the efficiency of scientific and technological achievements in colleges and universities. From a national perspective, most science and technology parks have set up a platform for scientific and technological achievements exchange, or a special query database of scientific and technological achievements, to facilitate exchange and cooperation between enterprises and university research results. But this kind of communication is only one of the means of science and technology communication, and the effect is relatively poor. Therefore, the park must continue to strengthen its own ability to communication, and the organizational, interpersonal, mass communication and other means can be used to enhance the awareness rate and attention of scientific and technological achievements in colleges and universities home and abroad, in order to further promote the transformation of scientific and technological achievements.

Second, the science park should continue to strengthen their own s capacity building, to further improve the quality of innovation and entrepreneurial talent training. Cultivating innovative and entrepreneurial talents is one of the basic functions of science park. At present, the domestic university science and technology park using innovation, there are four entrepreneurial talent training modes: knowledge-based, entrepreneurial practice, special project training, and competition activities. Some science and technology parks apply one or several of them, and some apply all of them. However, from the implementation, the results are not ideal. The reason is mainly because the innovation and entrepreneurship environment has not yet formed in colleges and universities, and the innovation and entrepreneurship of most teachers and students is generally low. Thus, to strengthen the popularization of innovation and entrepreneurship knowledge, and constantly improve the quality of teachers and students' innovation and entrepreneurship, is one of the important initiatives to further improve the quality of innovative and entrepreneurial talents.

Finally, the science and technology park continuously strengthen their own capacity building, to further enhance the civic science literacy in the university and even the region. The effective upgrading of the science and technology ability of the science and technology park will help to bring more scientific and technological knowledge to the teachers and students and the broad masses of the public. It can spread new scientific ideas, popularize new scientific knowledge, and lead scientific spirit and the mainstream cultural value, so as to im- 
prove the school teachers, students and the public values, then improve their ideas and behavior, and finally substantially increase scientific literacy. However, in the current working environment, most parks have not realized the significance, and the transformation of science and technology resources, channel construction, and the effect are still at a low level, to be improved urgently.

\section{The Goals of Capacity Construction of Scientific Popularization for Science and Technology Park}

\subsection{The Ultimate Goal}

The construction of scientific popularization is an important part of the capacity building of the science and technology park. Its ultimate goal is to construct the self-organizing and popularizing ability, so that the science and technology park has become a system with self-organizing function. A system to form a dissipative structure and access to self-organization development must have four conditions: 1) system is open; 2) system is away from the equilibrium state; 3) system has the non-linear effect; 4) there is a random fluctuation phenomenon [10].

Is the science park has the basic conditions of dissipative structure? The answer is definitely yes. First of all, the science system of park is an open system, and there is material exchange with the surrounding environment, a negative entropy flow input. Science and technology system would exchange material, energy and information with government controlling system, science and technology resource transformation system, service support system, production and marketing system, and social environment system, and the various types of information, new technology, personnel and funds constitute the negative entropy flow. Secondly, the park system is away from the balance state. For the internal needs of the scientific system, the types of science and technology, information platform, funding channels, and communication channels, their distribution and change must have dimensional uneven on operating costs, nature, operational efficiency, subject characteristics and others. Thirdly, the role of the elements of the system is non-linear. The internal components of the popularization system include subjects, objects, funds, information, science and technology needs, and so on, and the role of each element is interrelated, so that it can be determined that the role of each element is non-linear. For example, the public demand for science and technology will affect the funds flow direction, and thus affect the transmission of popular science knowledge, and ultimately affect the effectiveness of science and so on. Finally, there is a random fluctuation phenomenon in the science and technology system of the university science and technology park. There are two random fluctuations in the popularization system: external fluctuations and internal fluctuations. The external fluctuations include the sharp increase or sharp decline in public demand, the acceleration or slowdown in the pace of science and technology, the improvement or deterioration of the popular science environment, etc.; the internal ones include the ups and downs of science, the sharp increase or sharp decline in science efficiency and funds. 
These fluctuations will cause mutation in a certain time, and constitute the source of "creative destruction", so that the popularizing system would change from the original stable structure to dissipative structure [11].

\subsection{The Specific Goals}

Based on the above analysis, this paper argues that the self-organizing scientific popularization of university science and technology park means that the scientific research institutions and science and technology parks in colleges and universities, as well as enterprises can stimulate themselves in the process of popularization without the help of external specific forces (other organizations), and integrate resources and raise funds through relying on their own structure, so as to continuously expand the science and technology pathways in a variety of information platform. Thus, the scientific and technological resources in colleges and universities continue to be transformed into science resources and eventually transformed into the capacity of social productive forces. It mainly includes the promotion of self-organization ability of popularizing personnel, the ability of content promotion and self-organization and docking of demand, self-organization and delivery ability, self-organization and financing ability of fund.

\subsubsection{Ability of Personnel's Self-Organization of Popularizing Science}

The quality of science and technology personnel is an important factor in the quality of scientific popularization. In the process of universal popularization of science and technology, the personnel can study the professional knowledge with low cost, explore the methods and skills, so as to continuously improve their own quality of transmission and improve the effectiveness and efficiency of science and technology dissemination.

\subsubsection{Ability of Self-Organization and Delivery of Science Information}

In today's information society, only those enterprises who timely, comprehensively and effectively grasp dynamic scientific and technological information can be initiative in the fierce competition. The ability of self-organization and delivery of science information refers that the science subjects have the ability to collect, process and transmit scientific and technical information according to the needs of enterprises or the public in the popularization of science and technology. Specifically, the subjects will based on the needs of enterprises or the public collect, process and send a variety of scientific and technical information; in the transmission process it can select the means of sending and delivering information by themselves, as far as possible to overcome the information distortion, omissions, lag and other defects, to achieve the purpose of improving the efficiency of information transmission and delivery, reducing the cost.

\subsubsection{Ability of Pushing Popularization Content and Grasping Demand}

There are two aspects about the popularization of science and technology park. First, it should popularize scientific and technological achievements for the spe- 
cific needs of enterprises and social investment institutions; second, it should popularize science achievements for the general public (such as college teachers and students, the public, etc.). But both the former and the latter are in a highly discrete state. In this case, if there is no goal to carry out the popular science, it is easy to cause waste and the effect is not good; if completely for the discrete needs to carry out point-to-point science popularization, the cost is too high with low efficiency. If there is a public science community with high efficiency and low operating costs among public, community, business, universities, and the park, the problem can be solved in a large extent. In this process, the science subjects can actively contact the groups with different needs and reach a consensus on the community in the absence of government intervention, in order to achieve a sound and effective treatment of various problems in the process.

\subsubsection{Ability of Self-Financing Scientific Popularization}

Adequate funding is one of the important guarantees for the effective operation of the popular science system. To ensure the smooth flow of funds sources and improve the efficient use of funds is the essential requirements of the smooth operation of the popularizing science system. The self-financing ability refers to the subjects' ability of self-organization of science popularization can find new funds channels and strengthen the applied efficiency of funds in the popularization of science and technology. Aimed at projects such as high degree of materialization, high public demand and marketable operation, the popularizing subjects constantly expand the channels of popularization of science and technology funding, while continuously improve the efficiency of the use of funds through self-restraint, with various means, such as self-organized use of commercial investment, capital market, private capital and foreign capital.

\section{Factors Influencing Capability Construction of Scientific Popularization in Science Park}

The development of scientific popularization of science and technology park is affected by many factors, such as the science and technology awareness, the support of the competent department or local government, the transformation efficiency of science resources, the application of new communication methods, the relevant institutions, teachers, and students involved in the popularity of science, the actual ability of subjects and so on. But in the long run, the complex factors can be classified as the following four aspects.

\subsection{Environment of Scientific Popularization}

The basic environment of scientific popularization includes science and financial investment and policy support provided by local government for colleges and universities, the extent that the park value popularizing science, the quality of college teachers and students, as well as local citizens, the interaction between society and colleges, the application of advanced communication technology, and the establishment of the science education system, all of which have an im- 
portant impact on the scientific popularization of science and technology park.

\subsection{Popularizing Capacity of Science and Technology Resources}

Ren Fujun argued that the popularization of scientific and technological resources is to transform the science and technology resources into popularizing resources. This process is the extension and expansion of the function of science and technology resources from its own application scope, not affecting its attributes, but it has enriched and improved popularizing resources [5]. Therefore, in this sense, the ability of transforming scientific and technological resources is the main component of popularizing ability, which defines what should be popularized and enhance the scientific popularization in science and technology park. All along, the scientific and technological resources cannot be transformed into popularizing resources, which is a direct obstacle to the popularization. On the other hand, numerous resources in colleges and universities are not applied, causing waster; on the other hand, according to the survey, the total amount of China's science resources is limited, with less high quality resources, and the comprehensive utilization rate is low, causing repeated construction [5]. This is because of the low transformation rate of science and technology resources.

\subsection{Communication Capability of Science Park}

For an organization, the essence of its communication is the establishment or maintenance of "relationships". An organization with strong "communication ability" can achieve the establishment and maintenance of the relationship between itself and its target objects in the interdependence of the various elements and links of the communication process, so as to achieve the specific goals and interests of the organization. Science and technology park in colleges and universities, as a special organization different from the industrial and commercial organizations and different from the non-profit ones, has the following eight special communication abilities: ability of information, ability of relationship, ability of channels, ability of listening, ability of context, ability to target, ability to empathize, and ability to act. They basically cover all aspects and processes of science popularization, and ultimately focus on the establishment and maintain relationship internally and externally [12].

\subsection{Operational Capacity of Science and Technology Park}

The organizational operational capacity refers to the ability to manage and operate the organization to ensure its survival and sustainable development. It is mainly manifested in two aspects. One is the basic ability of the organization, including the conversion ability, innovation ability, integration ability; the other is the organization's special ability, including its own core competitiveness and being advanced [13]. Based on the above view, this paper argues that the operational capability of the science and technology park is its operational and man- 
agement ability in order to ensure the effective development of the popularization. Operational capacity is based on the internal management of the park, and its purpose is to ensure the smooth development of popularization. Management ability refers that the park popularizes science and technology in a benign circle, relying on their own advantages to obtain funds. Without the basic operational capacity, the effect of popularizing science must be greatly reduced, and there is no guarantee to carry out popularization. Therefore, the issue of operational capacity occupies an extremely important position in planning work of science parks, and its performance will directly influence the effective implementation of scientific popularization.

These four aspects affect the popularization of science and technology park, and jointly determine the strength. Among them, the ability of communication and the ability of transformation of science and technology resources are the core components, directly determining the actual level of popularization; the basic science environment and the operational capacity impact the sustainable and positive development of science popularization, so as to influence the power and potential of science park.

\section{Evaluation System of Capability Construction of Scientific Popularization in Science Park}

According to the connotation and influencing factors of the science popularizing ability of the science and technology park, combined with the current situation of the evaluation system of capability construction in our country, this paper divides the evaluation index of the science park into the evaluation index of basic quality and the special ability.

First of all, the evaluation index of basic quality can be built from the popularizing ability, the ability of science production and popularizing support ability. Secondly, according to several influencing factors of popularizing science, the evaluation index of special ability can be built.

\subsection{Evaluation Index of Basic Quality of Science and Technology Park}

\subsubsection{The Setting of Evaluation Index}

1) Investment Ability of Scientific Popularization

The indicators of investment of scientific popularization mainly cover science funds, popularizing facilities and staff configuration. The science funds are the sum of the cost of science and technology management, popularizing activities and facilities construction. This paper argues that the evaluation index of popularizing science fund can be the proportion of total expenditure of science expenditure, the amount of funds per capita, the amount of funds per capita. Popularizing facilities refer to the supporting facilities for popularizing science and activities, such as activity center and scientific and technological achievements exhibition center. The evaluation index can be the number and area of popular science places. Popularizing staff refers to the personnel of organization and im- 
plementation, and their quality is related to the quality of popularizing activities, so that it can be evaluated through the number of full-time scientific staff, part-time science staff, the proportion of highly educated scientific staff.

2) Productive Ability of Science Popularization

Productive ability of science popularization refers to the transformation and practice ability of the subjects of science and technology park through the science innovation activities to enhance the effectiveness of science. The transformation ability of science and technology park mainly refers to the ability of delivering and promoting scientific popularization through certain media. The evaluation index of this ability can be the circulation of newspapers, books, periodicals, $\mathrm{CD}$, radio and television show time, the network click rate and so on. Science and technology activities can be special exhibition, scientific competition, scientific days or weeks, and its index can be the number of the participator, the number of activities, the number of per capital activities, and the opening hours.

3) Supporting Ability of Scientific Popularization

Supporting ability refers to the comprehensive ability to maintain popularizing activities through the other conditions, and the supporting ability of science park should include innovation management ability and technological innovation ability. The innovation management ability is mainly to create a new and effective science resource integration paradigm for the park, which can be reflected through the evaluation of innovation strategy, mechanism, policy and organization operation efficiency. Technological innovation ability refers to the ability to use and implement new technologies, which will be the strong support of the science park, which can be evaluated through independent innovation product rate, market share and other indicators.

\subsubsection{Establishing Evaluation Index System of Basic Ability}

Based on the above evaluation index, this paper divides the index of the basic ability into three first-level indicators, seven second-level indicators, and 22 three-level indicators, all of which together constitute the following evaluation indexes System as shown in Table 1 [14].

\subsubsection{Establishment of Evaluation Index Weight of Basic Ability}

The establishment of the weight is mainly used to measure the importance of each indicator, and in general, the greater the weight, the higher the importance of indicators. The weight calculation is mainly through subjective empowerment, objective empowerment or a combination of the two. In a variety of ways, this paper mainly selects the analytic hierarchy process to establish the weight of each evaluation index of basic ability. Firstly, the factors related to the overall goal are decomposed into different hierarchical structures such as target layer (primary index), criterion layer (secondary index) and scheme layer (level index). On this basis, with the method of judging the matrix eigenvector, the average weight of the elements on each level of each element is obtained, and then 
Table 1. Evaluation indexes system of basic popularization ability of science park.

\begin{tabular}{|c|c|c|}
\hline $\begin{array}{c}\text { Target } \\
\text { (first-level indicators) }\end{array}$ & $\begin{array}{c}\text { Criterion } \\
\text { (second-level indicators) }\end{array}$ & Scheme (three-level indicators) \\
\hline \multirow{8}{*}{ Investment Ability } & \multirow{3}{*}{ Funds C1 } & Proportion C11 \\
\hline & & Financing amount per capita $\mathrm{C} 12$ \\
\hline & & Applying amount per capita C13 \\
\hline & \multirow{2}{*}{ Facilities C2 } & Number of sites C21 \\
\hline & & Site area C22 \\
\hline & \multirow{3}{*}{ Personnel C3 } & Full-time staff C31 \\
\hline & & Part-time staff C32 \\
\hline & & Proportion of high educated staff C33 \\
\hline \multirow{8}{*}{ Productive Ability } & \multirow{5}{*}{ Transmission C4 } & $\begin{array}{l}\text { Circulation of newspapers, } \\
\text { books, journals C41 }\end{array}$ \\
\hline & & Circulation of CD C42 \\
\hline & & Show time of radio and TV C43 \\
\hline & & Online clicking rate C44 \\
\hline & & Participator number C51 \\
\hline & \multirow{3}{*}{ Activities C5 } & Activity number C52 \\
\hline & & Participation per capita C53 \\
\hline & & Opening time of sites C54 \\
\hline \multirow{6}{*}{ Supporting Ability } & \multirow{4}{*}{ Innovative management $\mathrm{C} 6$} & Innovative strategy C61 \\
\hline & & Innovative mechanism C62 \\
\hline & & Innovative policy C63 \\
\hline & & $\begin{array}{l}\text { Operation efficiency of } \\
\text { innovative group C64 }\end{array}$ \\
\hline & \multirow{2}{*}{ Technological innovation C7 } & Independent innovative product rate $\mathrm{C} 71$ \\
\hline & & Market share C72 \\
\hline
\end{tabular}

Source: Adapted from [14].

with the weight the final weight of the program layer to the total target is gotten, and the optimal evaluation scheme is obtained [15]. This is a simple method for quantitative evaluation of non-quantitative indicators in systematic reviews. The simple steps are as follows:

1) Constructing judgment matrix

With $\mathrm{U}$ as the goal and $f_{i}$ as the evaluation factors, $f_{i} \in C(i=1,2,3, \cdots, n)$. $f_{i j}$ represents the relative importance of $f_{i}$ for $f_{j}$, and the degree of importance is $1,3,5,7,9$, respectively referring to that of equally important, slightly important, very important, obviously important, absolutely important, and with 2, 4, 6, 8 represent the intermediate value of the two adjacent ones [16].

2) Calculating the weights and verify the consistency

Through the U-C matrix, the unit eigenvector corresponding to the largest 
eigenvalue is calculated and the consistency verification is carried out. Finally, the components of the unit eigenvector are calculated as the required weight values.

3) A composite sort vector of the weight value (weight)

As the experts are different, there is a discrepancy between understanding of the objectives of the evaluation, which leads to different judgment matrices listed by different experts. And the processing of the weight needs the judgment matrix of each expert, to gain the weight of each target vector. Therefore, it is necessary to assume that the weight coefficient of each expert is equivalent, and then use the geometric mean comprehensive ranking vector method to deal with the weight vector, and finally get the weight of the integrated sort vector.

4) Combined with the above qualitative analysis, the weight of each program in the system can be clearly identified.

\subsubsection{Evaluation Model and Evaluation Standard}

The fuzzy evaluation method is applied.

1) Establish evaluation index factor set, which impacts evaluation index collection of scientific popularization of science and technology park.

2) Establish the weight set, and with the analytic hierarchy process determine the weight of the index.

3) Establish evaluation set, which is a set of evaluation results that may be made to evaluate the target, with $\left(V, V=\left(V_{1}, V_{2}, V_{3}, V_{4}, V_{5}\right)=\right.$ (good, good, general, poor, poor).

4) Evaluation matrix. According to the experts' assessment results, determine the composition of the single factor judgment matrix $W_{i}$.

5) Multi-level fuzzy evaluation. The first-order judgment matrix is obtained by the multi-level judgment matrix $W_{p}$ so that the fuzzy matrix is calculated and $Y_{i}=X_{i} * W_{i}$ is used as the upper evaluation index evaluation matrix $R y$.

Obtain the two-level comprehensive evaluation: $O=X * R y$

Set the weighting coefficient matrix $B=(9,7,5,3,2,1)$, and obtain the composite flat value: $I=O * B$.

If $I \in[1,2]$, it shows that the popularizing ability of science and technology park is poor; if $I \in(2,3)$, the basic ability is poor; if $I \in(3,5)$, the basic ability is general; if $I \in(5,7)$, the basic ability is good; if $I \in(7,9)$, the ability is very good.

\subsection{Evaluation Index of Special Ability}

\subsubsection{Setting of Evaluation Index of Special Ability}

As mentioned earlier, the evaluation index of science and technology capacity building in science and technology park includes two parts: basic ability and special ability. Therefore, it is necessary to set the evaluation index for the special ability. According to the factors of science and technology capacity-building, the following indicators set is made, as described in Table 2 [17].

First, the ability to transform science is transformation ability of science and technology resources, and its evaluation is mainly through the transformation 
Table 2. Evaluation indexes system of special popularization ability of science park.

\begin{tabular}{|c|c|}
\hline Transformation capacity & $\begin{array}{l}\text { Effect } \\
\text { Level }\end{array}$ \\
\hline \multirow{3}{*}{ Transmission capacity } & $\begin{array}{c}\text { Information } \\
\text { Relation } \\
\text { Channel }\end{array}$ \\
\hline & Target \\
\hline & $\begin{array}{c}\text { Listening } \\
\text { Context } \\
\text { Empathy }\end{array}$ \\
\hline \multirow{3}{*}{ Operation capacity } & Conversion \\
\hline & Integration \\
\hline & Control \\
\hline
\end{tabular}

Source: Adapted from [17].

effect and transformation level. The effect can be divided into two parts: the direct effect and the indirect effect. The transformation level can be divided into three parts: the quantitative level, the structure level and the quality level. Quantity and structure evaluations are related to people, finance, material and other resources, and the quality is evaluated through the novelty, interesting and advanced knowledge. Second, the ability to transmit science mainly covers the above eight capabilities. The information ability is to understand, obtain and use the information, including the analysis of information, evaluation, decisionmaking, the way to receive information, methods, the use of information to solve practical problems and many other aspects, as well as the use of information technology. The relationship ability focuses on the timely and comprehensive feelings and response. Channel capacity can be evaluated through the proportion and effect of the traditional channels and new channels. The target ability can be evaluated in terms of setting, planning, analysis, and so on. The rest listening, context, and empathy abilities determine the understanding and expression of popularization of the science language, which can be appropriate evaluated. Third, the scientific operational capacity includes conversion, integration, competition, and control. Conversion capacity can be evaluated by speed, supply and demand ratio and other aspects; integration capacity is assessed through the integration of all kinds of resources and information; competition capacity can be evaluated through comparing it with the other science and technology parks; evaluation of control ability focuses on that whether capacity building can develop according to the plan and whether construction errors can be corrected in time and so on.

\subsubsection{Weight Setting and Evaluation Index}

As the evaluation indicators of special ability are basically qualitative indicators, 
which cannot be accurately measured and assessed as quantitative indicators, the proposed Delphi method is applied to evaluate it. Delphi is the most traditional qualitative evaluation method, and the core is anonymously soliciting the opinions of the experts, through the organization of expert opinion summary, collation and feedback, so that the views of experts tend to be consistent, and ultimately get a unified and reliable conclusions or programs [18].

1) Select peer experts. Experts who have senior titles and rich practical experience, understand the characteristics of capacity construction, and engage in science and technology park management, capacity building of science popularization, and scientific research for many years should be selected. The number of experts is $R$, numbered $R_{1}, R_{2}, \cdots, R_{n}$.

2) Design an expert scoring table, through the literature and extensive solicitation of expert opinions, as well as reference to analysis methods of capacity-building system.

3) Establish evaluation set E, E = (poor, poor, general, well, well).

4) Perform the first round of expert ratings. Different experts evaluate the weight for different indicators, and collect their evaluation and do the statistical analysis. Calculate the average weight of each indicator, as the corresponding weight of the index $\left(Q_{1}, Q_{2}, \cdots, Q_{n}\right)$.

5) Perform a second round of expert ratings. According to the details of the scoring table, the experts score each of the evaluation indicators, with scores between $0-100$, and each expert's results on the index is recorded as $R_{1}\left(M_{1}, M_{2}, \cdots, M_{n}\right) ; R_{2}\left(M_{1}, M_{2}, \cdots, M_{n}\right) ; R_{3}\left(M_{1}, M_{2}, \cdots, M_{n}\right) \cdots$ $R_{n}\left(M_{1}, M_{2}, \cdots, M_{n}\right)$.

6) Collect and calculate. Set the final score for each expert evaluation as $s_{R 1}, s_{R 2}, \cdots, s_{R n}$, for each expert and each evaluation is obtained

$$
\begin{gathered}
s_{R_{1}}=Q_{1} * M_{1}+Q_{2} * M_{2}+\cdots+Q_{n} * M_{n} \quad\left(0<s_{R_{1}} \leq 100\right) \\
s_{R_{2}}=Q_{1} * M_{1}+Q_{2} * M_{2}+\cdots+Q_{n} * M_{n} \quad\left(0<s_{R_{2}} \leq 100\right) \\
\vdots \\
s_{R_{n}}=Q_{1} * M_{1}+Q_{2} * M_{2}+\cdots+Q_{n} * M_{n} \quad\left(0<s_{R_{n}} \leq 100\right)
\end{gathered}
$$

7) In order to ensure the fairness of the evaluation results, we need to remove one of the highest points and the lowest points from the top to get the average points. If $\mathrm{P} \in[60,69]$, the result is poor; if $\in[70,79]$, it is general; if $\mathrm{P} \in[80$, $89]$, it is good; if $\mathrm{P} \in[90,100]$, it is very good.

\subsection{Establishment of Evaluation Achievements of Capacity Building of Popularizing Science and Technology in Science Parks}

This paper argues that, as the evaluation includes basic ability and special ability evaluation, the final evaluation result should be the result of two parts. In this case, the results of the basic and the special evaluation index need to be set up.

1) Suppose the results as follows. I $1=$ Very Poor $=1, \mathrm{I} 2=$ Poor $=2, \mathrm{I} 3=$ Gen- 
eral $=3, \mathrm{I} 4=$ Good $=4$, I5 = Very Good $=5$;

2) Suppose the special ability evaluation results are followings. P1 $=$ Very Poor $=1, \mathrm{P} 2=$ Poor $=2, \mathrm{P} 3=$ General $=3, \mathrm{P} 4=$ Good $=4, \mathrm{P} 5=$ Very Good $=5$;

3) Assuming that the results of the basic ability evaluation are more important than the results of the special one, the weight of the two is $60 \%$ and $40 \%$ respectively; the value of I becomes $0.6,1.2,1.8,2.4,3$; the value of $\mathrm{P}$ is $0.4,0.8,1.2,1.6$, 2;

4) $\mathrm{d}$ Set the final evaluation results as $Z, Z=I * P$, and the calculation is in the following table:

\begin{tabular}{cccccc}
\hline $\mathrm{Z}$ & 0.6 & 1.2 & 1.8 & 2.4 & 3 \\
\hline 0.4 & 0.24 & 0.48 & 0.72 & 0.96 & 1.2 \\
0.8 & 0.48 & 0.96 & 1.44 & 1.92 & 2.4 \\
1.2 & 0.72 & 1.44 & 2.16 & 2.88 & 3.6 \\
1.6 & 0.96 & 1.92 & 2.88 & 3.84 & 4.8 \\
2 & 1.2 & 2.4 & 3.6 & 4.8 & 6 \\
\hline
\end{tabular}

5) Similarly, the conclusion is that if $Z \in(0,1.2)$, it shows that the overall science popularization ability of university science and technology park is very poor; if $Z \in(1.2,2.4)$, it is poor; if $Z \in(2.4,3.6)$, it is general; if $Z \in(3.6,4.8)$, it is good; if $Z \in(4.8,6)$, it is very good.

\section{Conclusion and Research in the Future}

Based on the previous research results, this paper gives the definition of science popularization ability in University Science Park, and then gives the definition of science popularization ability construction in University Science Park. Then, from the three aspects of the goal, function and influencing factors of science popularization capacity-building in University Science Park, the connotation of science popularization capacity-building in University Science Park is expounded.

From the two aspects of basic science popularization ability and special science popularization ability of University Science and Technology Park, the evaluation system of science popularization ability construction in University Science and Technology Park has been initially constructed. Of course, this evaluation system is still immature, because it lacks a large amount of empirical data to verify it. In this sense, the construction of University Science and Technology Park capacity-building evaluation system is a systematic project, and the final form of the evaluation system of University Science and Technology Park Science also needs to be combined with the actual repeated verification and trial and error, which should be completed together by scholars and experts of University Science and Technology Park.

\section{References}

[1] Fan, D.P. (2006) Improving the Public Scientific Literacy and the New Concept of 
Science Education. Journal of South China Normal University (Social Sciences Edition), No. 6, 9-14, 157.

[2] http://news.sciencenet.cn/htmlnews/2015/9/327326.shtm

[3] Li, Y.Q. and Wang, H.L. (2008) The Significance and Effective Ways of Popularizing Science by Colleges and Universities in the New. Tianjin Science and Technology, No. 6, 69-70.

[4] Shi, Z. (2013) Promoting the Construction of Popularizing Science Ability and Improving Innovation based on the Related Statements of the 18th Report. China Research Institute for Science Popularization. Tasks and Undertake of Scientific Popularization in China through Exploration Its Theory and Practice. Proceedings of the 20th National Symposium on Popular Science, China Research Institute for Science Popularization.

[5] Ren, F.J. (2009) Reflections on the Popularization of Scientific and Technological Resources. Science Popularization, No. 3, 60-65.

[6] Yu, J. (2005) On the Ability Construction of Science Popularization of Science and Technology Communities. Xuehui, No. 7, 48.

[7] Li, H. (2013) A Study on the Ability Construction of Science Popularization in Chinese Colleges and Universities. Journal of Architectural Education in Institutions of Higher Learning, 1, 151-154.

[8] Lei, M. (2005) Capacity Building Theory. Party School of Central Committee of CPC.

[9] He, X. (2002) The Burden Is Heavy to Carry out the "Science and Technology Popularization Law”. Xiamen Science and Technology, No. 5, 1-4.

[10] Wu, T. (2001) Research on Self-Organization Methodology. Tsinghua University Press, Beijing, No. 6, 28-66.

[11] Wu, X. (2011) A Theoretical Discussion on the Promoting Self-Organization and Promotion Ability of Agricultural Technology. Research of Agricultural Modernization, 4, 457-460.

[12] Ren, X.Y. (2014) Research on Organizational Communication Ability. Lanzhou University, Lanzhou.

[13] Zhang, D. (2008) The Flexibility and Improvement of Operating Ability of Manufacturing Enterprises. Harbin Institute of Technology.

[14] Zhang, L., Zhang, X. and Chen, F. (2015) Evaluation and Analysis of Regional Science Popularization Ability Based on Fractal Model. Science and Technology Management Research, 2, 44-48.

[15] Wang, W., Zhao, T., Xin, G. and Xu, B. (2016) Comprehensive Ranking of Product Attributes Based on Analytic Hierarchy Process. Journal of Communications, 37, 88-94.

[16] Ma, W., Jiang, L. and Gao, Y. (2007) Fuzzy Comprehensive Evaluation and Case Study of Educational Technology Training Performance of Primary and Secondary School Teachers. China Education Information Technology, No. 6, 70-73.

[17] He, L. (2015) Index System Construction of Enterprise Science Popularization. Science Research Management, S1, 465-469.

[18] Tian, X.R. (2012) Force, Should Be Guangxi. The Application of Delphi Technique Method in Sichuan Province NCMS. Soft Science of Health, 26, 844-847. 